Table 1. Proportion of patients with a valid RA diagnosis ${ }^{1}$ as a function of RF and aCCP laboratory results

\begin{tabular}{|c|c|c|c|c|}
\hline \multirow[t]{2}{*}{ Test Result } & \multicolumn{3}{|c|}{$\mathrm{aCCP}$} & \multirow[b]{2}{*}{ Total } \\
\hline & Not Available $(0)^{2}$ & Negative (-) & Positive (+) & \\
\hline $\begin{array}{l}\text { Rheumatoid } \\
\text { Factor }\end{array}$ & $\begin{array}{c}\text { Negative (-) } \\
\text { N } 810 \\
\text { RA 86.3\% } \\
\text { Poss RA 3.9\% } \\
\text { Positive (+) } \\
\text { N 2,229 } \\
\text { RA 94.6\% } \\
\text { Poss RA 0.0\% } \\
\text { Total } \\
\text { N 3,039 } \\
\text { RA 90.7\% } \\
\text { Poss RA 1.9\% }\end{array}$ & $\begin{array}{c}N 427 \\
\text { RA }^{4} 89.7 \% \\
\text { Poss }^{5} \text { RA } 5.9 \% \\
\text { N } 5,308 \\
\text { RA 65.3\% } \\
\text { Poss RA } 11.9 \% \\
\text { N 2,566 } \\
\text { RA 78.0\% } \\
\text { Poss RA 8.5\% } \\
\text { N } 8.301 \\
\text { RA } 76.1 \% \\
\text { Poss RA 9.2\% }\end{array}$ & $\begin{array}{c}\text { N } 1,159 \\
\text { RA } 98.2 \% \\
\text { Poss RA 0.0\% } \\
\text { N 2,005 } \\
\text { RA } 94.5 \% \\
\text { Poss RA 0.0\% } \\
\text { N } 12,978 \\
\text { RA 95.8\% } \\
\text { Poss RA 2.1\% } \\
\text { N } 16,142 \\
\text { RA } 95.9 \% \\
\text { Poss RA 0.5\% }\end{array}$ & $\begin{array}{c}\text { N } 1,586 \\
\text { RA } 93.5 \% \\
\text { Poss RA 3.2\% } \\
\text { N } 8,123 \\
\text { RA } 80.7 \% \\
\text { Poss RA } 5.8 \% \\
\text { N } 17,773 \\
\text { RA } 87.6 \% \\
\text { Poss RA 4.3\% } \\
\text { N } 27,482 \\
\text { RA } 85.9 \% \\
\text { Poss RA } 4.7 \%\end{array}$ \\
\hline
\end{tabular}

${ }^{1}$ Diagnosis given by the treating rheumatologist. ${ }^{2}$ No test results available or test results available but without normal range values. ${ }^{3} 1,253$ patients without available or interpretable RF or aCCP excluded from initial cohort. ${ }^{4}$ Percent of 553 charts reviewed confirmed as RA. ${ }^{5}$ Poss RA = Possible RA. Patients met our inclusion criteria but the treating rheumatologist never made definitive diagnosis of RA or alternative diagnosis (from 553 charts reviewed).

The percentage of RA-confirmed patients with one test not available, whose complementary test was negative (RFO/aCCP- or RF-/aCCPO), was greater than of patients for whom both tests were negative (RF-/aCCP-). This suggests our data extraction methods may be incomplete or that unidentified bias may be present and warrants further study.

Conclusion: Our methodology for constructing an RA database by selecting patients with $\geq 2$ rheumatology clinic visits, $\geq 1$ ICD-10 diagnosis of $R A$, and treatment with $\geq 1$ DMARD, has high positive predictive value for RA. Positive RF and aCCP test results were strong predictors of rheumatologists' diagnostic certainty for an RA diagnosis. Thus, the VANRAD database and the associated EHR provide opportunity for a wide range of retrospective observational and prospective longitudinal studies based on 'real-world' patient care.

REFERENCES:

[1] Ng B, et al. Arthritis Care Res 2012;64:1490-6; Hanly JG, et al. Open Access Rheumatol 2015;7:69-75.

Acknowledgements: This study was sponsored by Bristol Myers Squibb. Disclosure of Interests: Amy Joseph Speakers bureau: Speakers bureau in the distant past., Grant/research support from: Bristol Myers Squibb, Jodi Yanagida: None declared, Xinliang Huang: None declared, Prabha Ranganathan: None declared, Melissa Laurie Shareholder of: Bristol-Myers Squibb, Employee of: I am currently employed by Bristol Myers Squibb., Hong Xian Grant/research support from: Bristol Myers Squibb Co., Seth Eisen Grant/research support from: The effort presented in this Abstract was supported with funds provided by Bristol-Meyers Squibb.

DOI: 10.1136/annrheumdis-2021-eular.2519

\section{AB0129 IL-6R GENETIC VARIANTS AS PREDICTORS OF CLINICAL RESPONSE TO TOCILIZUMAB IN RHEUMATOID ARTHRITIS PATIENTS}

L. Sainz Comas ${ }^{1}$, P. Riera ${ }^{2}$, P. Moya ${ }^{1}$, S. Bernal ${ }^{3}$, A. Lasa $^{3}$, S. Jeria Navarro ${ }^{1}$, D. Lobo Prat ${ }^{1}$, H. Codes ${ }^{1}$, I. Castellví ${ }^{1}$, C. Díaz-Torné ${ }^{1}$, A. Laiz ${ }^{1}$, B. Magallares ${ }^{1}$ A. M. Millán Arciniegas ${ }^{1}, \mathrm{H}$. Park ${ }^{1}, \mathrm{H}$. Corominas ${ }^{1} .{ }^{1}$ Hospital de la Santa Creu $i$ Sant Pau, Rheumatology, Barcelona, Spain; ${ }^{2}$ Hospital de la Santa Creu i Sant Pau, Pharmacy/Genetics, Barcelona, Spain; ${ }^{3}$ Hospital de la Santa Creu i Sant Pau, Genetics, Barcelona, Spain

Background: Rheumatoid arthritis (RA) is a chronic, systemic, inflammatory autoimmune disease of unknown etiology. Tocilizumab (TCZ) is a first-line biological disease-modifying anti-rheumatic drug (bDMARD) which inhibits Interleukin 6 (IL-6) pathway through blockade of its receptor. At present, there is a lack of evidence to recommend the treatment of one bDMARD over another.(1) Seeking for genetic biomarkers to predict response to treatment could be key towards a personalized treatment strategy in rheumatology.(2)

Objectives: We aimed to evaluate whether functional single nucleotide polymorphisms (SNPs) in the IL6R gene could predict response and/or toxicity to TZC in Caucasian patients diagnosed with RA.

Methods: Retrospective analytical preliminar study of a cohort of 31 patients diagnosed with RA (ACR/EULAR 2010 criteria) who received treatment with TCZ within the last 10 years. Epidemiological, clinical and laboratory data were collected. DNA was extracted from EDTA blood samples. Three SNPs in the IL-6 receptor gene (rs12083537, rs2228145, rs4329505) were genotyped by realtime PCR with TaqMan probes. The associations between polymorphisms and clinicopathological features were evaluated using parametric tests. Efficacy was assessed as the difference of DAS-28 CRP at 6 months. The toxicities recorded were hepatotoxicity, infections, hypersensibility, gastrointestinal, hematological and dyslipidemia.

Results: The 31 DNA samples from patients included were mainly female $(83.9 \%)$ and had a mean age at diagnosis of 46.8 years. The mean duration of treatment was 51.3 months and, previously to initiate TCZ, they received a mean of 2,6 csDMARD and 1,7 bDMARD.

The more frequent adverse effects were hypertransaminasemia (22.6\%) and neutropenia (32.3\%). Most relevant epidemiologic and clinical data is shown in Table 1.

Table 1. Clinical characteristics. $R A=R$ heumatoid Arthritis. $C C P=$ anti-Cyclic Citrullinated Peptides. $R F=$ Rheumatoid factor. csDMARDs= conventional synthetic Disease-modifying antirheumatic drug. bDMARD biological Disease-modifying antirheumatic drug. BMI=Body Mass Index. $\mathrm{Sc}=$ subcutaneous. Ev=endovenous. DAS28= Disease Activity Score in 28 joints

$\operatorname{Sex}(\mathrm{n}=31), \mathrm{n}(\%$ women/men)

Age at diagnosis $(n=31)$, years +- SD

Erosive RA $(n=31), n(\%)$

Anti-CCP positive $(n=31), n(\%)$

UI+- SD

RF positive $(n=31), n(\%)$

UI+-SD

Previous csDMARD $(n=31)$, $n^{\circ}+-S D$

Previous bDMARD $(n=31), n^{\circ}+-S D$

BMI $(n=29)$, mean $+-S D$

Duration of treatment $(n=31)$, months $+-S D$

-Active treatment $(n=12)$

-Finished treatment $(n=19)$

Route of administration ( $\mathrm{n}=31), \mathrm{n}(\%) \mathrm{sc} / \mathrm{ev}$

Basal DAS28 $(n=30)$, mean+- SD

DAS28 reduction at 6 months $(n=28)$, mean+-SD

$26 / 5(83,0 \% / 16,1 \%)$

$46,8+-12,8$

$14(45,2 \%)$

$23(74,2 \%)$

$259,7+-137,3$

$21(67,7 \%)$

$189,4+-114$

$2,6+-1,3$

$1,7+-1,4$

$29,3+-5,1$

$51,3+-36,3$

$-80,9+-18,3$

$-32,6+-32,2$

$11 / 20(35,5 / 64,5)$

$5,3+-1,1$

$2,9+-1,1$

The univariate analyses showed that the rs2228145 variant was statistically associated with differences in DAS28 reduction at 6 months $(p=0.042)$. Regarding efficacy, we also found a trend with the SNP rs4329505 ( $p=0.173)$, which could achieve statistical significance with the projected inclusion of more patients. No associations were found regarding adverse effects.

Conclusion: The rs2228145 polymorphisms in the IL6R gene may be considered as a pharmacogenetic biomarker of TCZ response in RA patients. More studies are required in order to investigate the clinical use of pharmacogenetic biomarkers in rheumatic diseases.

\section{REFERENCES:}

[1] Smolen, Josef S., Robert B., et al. 2020. "EULAR Recommendations for the Management of Rheumatoid Arthritis with Synthetic and Biological Disease-Modifying Antirheumatic Drugs: 2019 Update." Annals of the Rheumatic Diseases 79 (6): 685-99.

[2] Tarnowski, Maciej, Agnieszka Paradowska-Gorycka, et al. 2016. "The Effect of Gene Polymorphisms on Patient Responses to Rheumatoid Arthritis Therapy." Expert Opinion on Drug Metabolism \& Toxicology 12 (1): 41-55.

Disclosure of Interests: None declared

DOI: 10.1136/annrheumdis-2021-eular.2615

\section{$\mathrm{AB} 0130$ \\ QUESTIONING THE USEFULNESS OF CDAI AS A MEASURE OF DISEASE ACTIVITY IN A TREAT TO TARGET PROGRAMME}

C. Lally ${ }^{1}$, I. Ali ${ }^{1}$, C. Silke ${ }^{1}$, B. Whelan ${ }^{1}$, M. O'sullivan ${ }^{1} .{ }^{1}$ Manorhamilton, Rheumatology, Manorhamilton, Ireland

Background: Rheumatoid arthritis (RA) is a chronic autoimmune condition which if not treated can lead to joint destruction and long term disability. In RA, the concept of T2T is recommended as the appropriate method to manage early arthritis ${ }^{1}$. It has shown promising results to achieve clinical remission $(C R)$ or low disease activity (LDA) ${ }^{2}$

Objectives: The objective of this study was to investigate the potential to achieve remission or LDA according to the Clinical Disease Activity Index (CDAI) for RA during treatment with Disease-Modifying Anti-Rheumatic Drugs (DMARDs) and Biologics, and the factors that affect the remission/LDA outcome.

Methods: We performed an observational prospective study on patients' data available from our Early Arthritis Cohort. All patients with newly diagnosed RA who met the American College of Rheumatology (ACR) criteria were enrolled. Patients are managed by an Advanced Nurse Practitioner (ANP) with consultant supervision. To assess their response to treatment, we used the Clinical Disease Activity Index ${ }^{3}$. Analysis was performed using SPSS.

Results: Out of a total of 459 patients, 353 completed the programme. 217 patients (61.5\%) were female and (136) $38.5 \%$ were male. Mean age was 53.98 (SD 14.66). 195 patients were on monotherapy, 40 on combination DMARDs and 
115 were on Biologics/Janus Kinase Inhibitors (JAK-Inh). Remission-rates in the monotherapy and combination DMARDs groups were approximately $60 \%$, whilst the remission rate in the Biologics/JAK-Inh group was $41.7 \%$. Amongst female patients $15.9 \%$ had erosions on X-ray at the time of diagnosis whilst the equivalent figure for male patients was $29.6 \%$.

Conclusion: An association between male gender and the likelihood of erosions on X-Ray was observed. In addition an association between final medication and outcome was observed. An increased likelihood of non-remission was noted in patients that required escalation to Biologics/JAKs. A possible explanation for the lower levels of remission seen throughout the groups is the difficulty in achieving remission under the CDAI score as compared to DAS-28.

\section{REFERENCES:}

[1] Smolen JS, Breedveld FC, Burmester GR, Bykerk V, Dougados M, Emery P, et al. Treating rheumatoid arthritis to target: 2014 update of the recommendations of an international task force. Annals of the Rheumatic Diseases. 2016;75(1):3

[2] Scott IC, Ibrahim F, Panayi G, Cope AP, Garrood T, Vincent A, Scott DL, Kirkham B; TITRATE Programme Investigators. The frequency of remission and low disease activity in patients with rheumatoid arthritis, and their ability to identify people with low disability and normal quality of life. Semin Arthritis Rheum. 2019 Aug;49(1):20-26. doi: 10.1016/j.semarthrit.2018.12.006. Epub 2018 Dec 28. PMID: 30685064.

Disclosure of Interests: None declared

DOI: 10.1136/annrheumdis-2021-eular.2629

\section{AB0131 DIFFERENCES IN CLINICAL PARAMETERS AND LABORATORY DATA OF RHEUMATOID ARTHRITIS PATIENTS IN REMISSION OR WITH LOW DISEASE ACTIVITY TREATED WITH BIOLOGIC AGENTS OR JANUS KINASE INHIBITORS}

$\underline{\text { Y. Hirano }}^{1}$, J. Hasegawa ${ }^{1}$, H. Kosugiyama ${ }^{2}$, D. Kihira ${ }^{2}$, K. Hattori'. ${ }^{1}$ Toyohashi Municipal Hospital, Rheumatology, Toyohashi, Japan; ${ }^{2}$ Nagoya University Graduate School of Medicine, Orthopaedic Surgery and Rheumatology, Nagoya, Japan

Background: There are four kinds of drugs for rheumatoid arthritis (RA) patients who are refractory or intolerant to methotrexate (MTX) or other conventional synthetic disease-modifying anti-rheumatic drugs, namely, tumor necrosis factor inhibitors (TNFi), inteleukin-6 inhibitors (IL-6i), abatacept (ABT) and Janus kinase inhibitors (JAKi). Although these drugs have distinct mechanism of action (MOA) to reduce disease activity of RA, the effects of these drugs of reducing disease activity or inhibiting joint damage are similar according past clinical trials. However, their different MOA may induce different change in body of RA patients. If there are some differences in body of RA patients treated different drugs which have different MOA, some differences may appear in clinical parameters and laboratory data we clinician are able to know in daily clinical practice.

Objectives: This retrospective cross-sectional study assessed differences in clinical parameters and laboratory data in RA patients who met the treatment goal with biologic agents $(\mathrm{BIO})$ or JAKi.

Methods: Data from the Toyohashi RA database (TRAD) was used. The TRAD is a collection of single-center retrospective data. Participants were BIO- or JAKtreated RA patients with clinical disease activity remission (REM) or low disease activity (LDA) [clinical disease activity index (CDAI) $\leq 10$ ]categorized by BIO treatment with TNFi (reference), IL-6i, or ABT, and JAKi treatment. Clinical parameters [tender joint counts (TJ), swollen joint counts (SJ), patient's global assessment (PtGA), patient's pain assessment (PainVAS), physician's global assessment (PhGA) and modified health assessment questionnaire (mHAQ)] and laboratory data [C-reactive protein (CRP), erythrocyte sedimentation rate (ESR), matrix metalloprotease-3 (MMP-3), white blood cell counts (WBC), hemoglobin $(\mathrm{Hb})$, platelet cell counts (PLT), neutrophils counts (Neut), lymphocyte counts (Lymph) and estimated glomerular filtration rate (eGFR)] were investigated in cross-sectional manner. They are statistically compared using the Dunnett test.

Results: 171 TNFi, 71 IL-6i, 50 ABT, and 18 JAKi cases are categorized in REM or LDA. Patients' characteristics (means) are as follows (TNFi/IL-6i/ABT/JAKi). Age (63.1/63.7/72.4/60.6; years old), RA duration (17.0/12.7/18.2/11.3; years), \%female (83.0/71.8/88.0/83.3), \%rheumatoid factor positive (81.9/80.3/90.0/88.9), \%anti-cyclic citrullinated peptide antibody (84.6/74.6/97.9/73.3), \%prednisolone (PSL) concomitant (3.5/4.2/18.0/11.1) and \%MTX concomitant (77.2/15.5/26.0/83.3). Parameters with statistical significance (means) were: TNFi/IL-6i-ESR 34.5/14.0 mm/hr, MMP-3 47.5/71.9ng/ $\mathrm{mL}$, WBC 6124/5404 / $\mu \mathrm{L}$, Lymph 2112/1646 $\mu \mathrm{L}$; TNFi/ABT-TJ 0.4/1.0, PtGA 13.3/20.0 mm, PainVAS 15.7/21.6mm, PhGA 7.4/11.1 mm, CRP 0.1/0.4 mg/dL, ESR 34.5/44.2 mm/hr, MMP-3: 47.5/72.9ng/mL, Lymph 2112/1816 $\mu \mathrm{L}$, Neut $3364 / 4233 \mu \mathrm{L}$, eGFR $75.4 / 65.3 \mathrm{~mL} / \mathrm{min} / 1.73 \mathrm{~m}^{2}$; and TNFi/JAKi-PLT 21.7/29.3 104/ $\mu \mathrm{L}$, Lymph 2112/1326 $\mu \mathrm{L}$

Conclusion: Although differences of rates of administering concomitant PSL or MTX should be considered, clinical parameter and laboratory data differences result from differences in the targeted cytokine between TNFi and IL-6i, differences in patient characteristics between TNFi and ABT, and differences in the MOA between TNFi and JAKi.

Disclosure of Interests: None declared

DOI: 10.1136/annrheumdis-2021-eular.2771

\section{$\mathrm{AB} 0132$ \\ THE STUDY OF SUBCLINICAL SYNOVITIS DETECTED BY ULTRASONOGRAPHY AND MRI IN RA PATIENTS AFTER REACHING CLINICAL REMISSION ON PATIENT'S SUBJECTIVE SYMPTOMS}

M. Nawata ${ }^{1,2}$, K. Someya ${ }^{1,2}$, T. Aritomi ${ }^{1,2}$, M. Funada ${ }^{2}$, K. Nakamura ${ }^{3}$, S. Kazuyoshi, ${ }^{1,2}$, Y. Tanaka ${ }^{2} .{ }^{1}$ Tobata General Hospital, Department of Clinical Immunology and Rheumatology, Kitakyushu, Japan; ${ }^{2}$ School of Medicine, University of Occupational and Environmental Health, Japan, The First Department of Internal Medicine, Kitakyushu, Japan; ${ }^{3}$ Tobata General Hospital, Department of Radiology, Kitakyushu, Japan

Background: The goal of treatment in rheumatoid arthritis (RA) is to achieve remission. There is the patient with residual symptoms in the Japanese RA patient who achieved clinical remission. There are not many studies to examine the relation between everyday life, social activity and evaluation of disease activities using high-sensitivity image examinations (musculoskeletal ultrasound (MSKUS) and MRI).

Objectives: To examine the relationship between subjective residual symptoms and imaging examinations in RA patients who have achieved clinical remission. Methods: 30 RA patients who achieved SDAI remission during RA treatment Age, sex, disease duration, physical findings, serological markers, disease activity, HAQ, EQ-5D-5L, FACIT-F, Patient Reported Outcomes (PROs), EGA and medications were evaluated. 44 joints were assessed by MSKUS with gray scale (GS) and power doppler (PD) and contrast-enhanced bilateral joint MRI scoring with OMERACT-RAMRIS scoring.

Results: 1. The mean SDAl of the 30 RA patients was 1.3. 2.In the analysis of the presence or absence of subjective residual symptoms that led to remission of SDAI (Table 1)

Table 1.

\begin{tabular}{lcccc}
\hline & $\begin{array}{c}\text { Subjective residual } \\
\text { symptoms/presence } \\
(\mathbf{N}=\mathbf{1 7})\end{array}$ & $\begin{array}{c}\text { Subjective residual } \\
\text { symptoms/ } \\
\text { absence }(\mathbf{N}=\mathbf{1 3})\end{array}$ & $\begin{array}{c}\text { Univariate } \\
\text { analysis } \\
\mathbf{p} \text { value }\end{array}$ & $\begin{array}{c}\text { Multivariate } \\
\text { logistic analysis } \\
\mathbf{p} \text { value }\end{array}$ \\
\hline TJC & $0.0 \pm 0.0$ & $0.3 \pm 0.5$ & 0.0173 & \\
HAQ & $0.4 \pm 0.4$ & $0.05 \pm 0.1$ & 0.0095 & 0.00181 \\
EQ5D-5L & $0.8 \pm 0.1$ & $0.9 \pm 0.0$ & 0.0001 & \\
FACIT-F & $14.5 \pm 9.8$ & $4.6 \pm 4.3$ & 0.0233 & \\
Morning stiffness (min) & $256.5 \pm 564.8$ & $0.0 \pm 0.0$ & 0.0210 & \multirow{2}{*}{0.0455} \\
Pain (VAS) (mm) & $9.2 \pm 9.5$ & $0.9 \pm 1.5$ & 0.0044 & \\
PGA (mm) & $7.7 \pm 9.0$ & $0.5 \pm 1.1$ & 0.0013 & \\
\hline
\end{tabular}

(1). In the univariate analysis, the number of tender joints, HAQ, EQ-5D-5L, FAC IT-F, morning stiffness, and pain VAS were extracted with significant differences. (2). In multivariate logistic analysis, $H A Q$ and pain VAS were extracted as independent factors with significant differences. 3.In univariate analysis of the association between HAQ and pain VAS extracted in multivariate logistic analysis and imaging examinations (MSKUS/MRI), MRI-synovitis was extracted with a significant difference in $\mathrm{HAQ}$.

Conclusion: 1. It was suggested that Pain VAS and HAQ due to RA could be identified in patients reaching SDAI remission. 2. In patients reaching SDAI remission, Pain VAS $\leq 10$ or $\mathrm{HAQ} \leq 0.5$ suggested that subjective residual symptoms may be eliminated. 3 . $H A Q \leq 0.5$ suggests that synovitis is less likely to be detected on MRI. 4. In patients who have reached SDAI remission, little residual inflammation was observed on US, suggesting that induction of remission is important not only to prevent joint destruction, but also to improve and maintain long-term QoL.

Disclosure of Interests: MASAO NAWATA Grant/research support from: I have received research funding from Eli Lilly Japan K.K., Kazuki Someya: None declared, Takafumi Aritomi: None declared, Masashi funada: None declared, Katsumi Nakamura: None declared, SAITO KAZUYOSHI Grant/research support from: I have received research funding from Eli Lilly Japan K.K., Yoshiya Tanaka Speakers bureau: I have received speaking fees from Abbvie, Daiichi-Sankyo, Chugai, Takeda, Mitsubishi-Tanabe, Bristol-Myers, Astellas, Eisai, Janssen, Pfizer, Asahi-kasei, Eli Lilly, GlaxoSmithKline, UCB, Teijin, MSD, and Santen Consultant of: I have received consulting fees from Abbvie, Daiichi-Sankyo, Chugai, Takeda, Mitsubishi-Tanabe, Bristol-Myers, Astellas, Eisai, Janssen, Pfizer, Asahi-kasei, Eli Lilly, GlaxoSmithKline, UCB, Teijin, MSD, and Santen Grant/research support from: I have received research grants from Mitsubishi-Tanabe, Takeda, Chugai, Astellas, Eisai, Taisho-Toyama, Kyowa-Kirin, Abbvie, and Bristol-Myers

DOI: 10.1136/annrheumdis-2021-eular.2830 